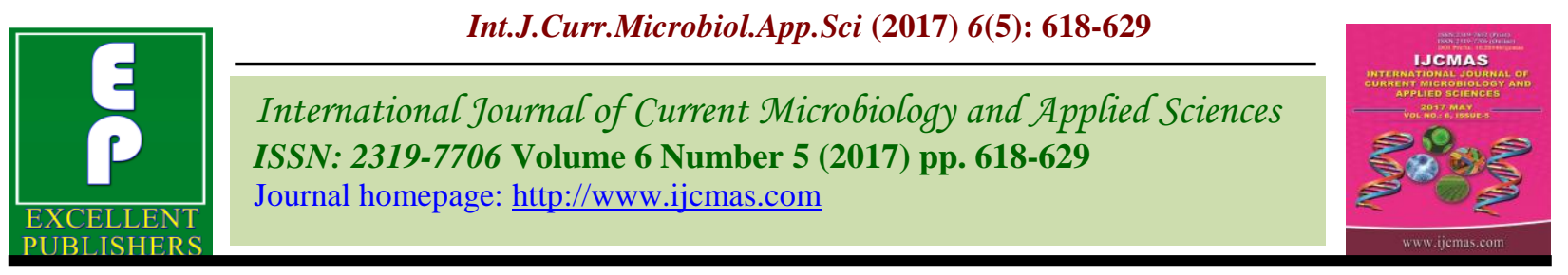

Original Research Article

https://doi.org/10.20546/ijcmas.2017.605.072

\title{
Importance of WPC 70 and Calcium Caseinate on Sensory and Textural Properties of Milk Fermented with $L$. rhamnosus
}

\author{
Rekha S. Patel and Subrota Hati* \\ Department of Dairy Microbiology, AAU, Anand-388110, Gujarat, India \\ *Corresponding author
}

\begin{tabular}{|c|c|}
\hline & A B S T R A C T \\
\hline $\begin{array}{l}\text { Ke y w o r d s } \\
\text { Dahi, } \\
\text { L. rhamnosus, } \\
\text { shelf life, sensory } \\
\text { attributes, } \\
\text { Textural profiles. }\end{array}$ & \multirow{3}{*}{$\begin{array}{l}\text { Product was prepared using optimized } 1.5 \% \text { WPC } 70 \text { or } 2.0 \% \text { Ca-caseinate for } L \text {. } \\
\text { rhamnosus MTCC } 5945 \text { (NS4) culture. These products were evaluated for its } \\
\text { storage stability at refrigeration temperature }\left(7 \pm 2^{\circ} \mathrm{C}\right) \text {. Sensory attributes of } 1.5 \% \\
\text { WPC, } 2.0 \% \text { Ca-caseinate and control dahi were analyzed up to } 15 \text { days at intervals } \\
\text { of } 5 \text { days at refrigeration temperature. Dahi supplemented with WPC } 70 \text { had } \\
\text { improved scores for flavour, body \& texture, acidity, colour \& appearance and } \\
\text { overall acceptability as compared to control and Ca-caseinate supplemented dahi. } \\
\text { All of these products were analyzed for textural profiles during refrigerated } \\
\text { storage }\left(7 \pm 2^{\circ} \mathrm{C}\right) \text { for } 15 \text { days. Textural profiles showed that } 1.5 \% \text { WPC or } 2.0 \% \\
\text { Ca-caseinate supplemented in dahi samples which prepared using NS4 culture had } \\
\text { better texture properties as compared to control during storage at refrigerated } \\
\text { temperature. }\end{array}$} \\
\hline Article Info & \\
\hline $\begin{array}{l}\text { Accepted: } \\
\text { 04 April } 2017 \\
\text { Available Online: } \\
10 \text { May } 2017\end{array}$ & \\
\hline
\end{tabular}

\section{Introduction}

Since time immemorial, human beings have made use of lactic acid bacteria (LAB), which are distributed widely in nature. LAB has traditionally been employed to produce fermented milk products, including yoghurt, leiben, dahi, lassi, shrikhand, kefir and koumiss (Miyazaki and Matsuzaki, 2008). Milk, although a rich growth medium, contains low concentration of free amino acids and peptides to efficiently support growth of LAB (Vasiljevic et al., 2005). LAB are the most common microorganisms found in dairy products and therefore are one of the most extensively studied groups of microorganisms, of which Lactobacillus, Lactococcus, Streptococcus and Bifidobacterium genera are most common
(Christensen et al., 1999). Fermented milk products are significantly more digestible than the processed milk (Tamime and Robinson, 1999).

Fermentation is a method that has been used for thousands of years to provide longer shelf life for perishable foods and to increase the flavor and odour of final food products. Fermentation is carried out by yeast, molds or bacteria. During the growth of these microorganisms, fermented foods are produced incidentally (Gahruie et al., 2015). Dahi (Sanskrit: Dadhi) is considered as the oldest Indian fermented milk product, which is similar to Western Yoghurt in most aspects except a few parameters such as type of 
culture, incubation temperature, principle flavor compounds, type of milks and its total solids. Similar products are known by different names throughout the world, viz. Laben in Egypt, Matzoon in Armenia, Gioddu in Italy, Naga in Bulgaria, etc. Some of the fermented milks and different types of dahi consumed throughout India have been categorized as follows:

North Zone: Dahi, Lassi

South Zone: Dahi, Buttermilk (Mattha)

East Zone: Payodhi or Laldahi or Mishtidoi

West Zone: Shrikhand, Chakka, Chhash, Dahi

Dahi contains various strains of LAB. For dahi fermentation, a small portion of product containing microbes of a previous fermentation (back slopping) is generally added to milk. However, production of dahi with an individual culture of Lactococcus lactis (Yadav et al., 2006) or a combination of cultures containing Lactobacilli and Lactococci (Yadav et al., 2007) was reported. Currently, India is the largest milk producer in the world with an annual milk production of about 140 million tones (NDDB, 2014). About $7 \%$ of the total annual milk produced in India is utilized for dahi preparation for direct consumption and this sector is showing an annual growth rate of more than $20 \%$ per annum (Singh, 2007). Dahi accounts for around $90 \%$ of the total cultured milk products produced in India (Behare and Prajapati, 2007).

WPC also provide nutrition to the LAB during fermentation as well as give compact body and texture with low wheying off in fermented milk products like dahi, yoghurt. Akalin et al., (2007) used WPC (1.5\%, w/v) in reduced-fat probiotic yoghurt. They observed that addition of WPC to yoghurt increased the buffering capacity around $\mathrm{pH} 4$ which controlled the progress of acidification during storage. They reported that this effect of WPC on slow acidification in probiotic yoghurt contributed to the enhanced shelf life of the product. Whey protein concentrate supplemented yoghurt exhibited improved viability and survival rate of $S$. thermophilus and $B$. animalis until the 21 day of storage. They attributed the growth promoting activity obtained by WPC to its whey protein content.Fortification of the milk base is one of the most important steps that enhances functional and nutritional properties and prevents textural defects such as poor gel firmness and syneresis as assessed by sensory evaluations and instrumental measurements (Marafon et al., 2011). Pal et al., (2010) found that supplementation of whey protein in over weight/obese individuals for 12 weeks decreased total cholesterol and LDL cholesterol levels compared with casein and control (glucose). These results indicated that whey protein supplementation can significantly improve metabolic risk factors associated with chronic diseases in overweight and obese individuals.

Damin et al., (2009) studied supplementation of milk with SMP, WPC and $\mathrm{Na}-\mathrm{Cn}$ at different levels caused a number of changes in the acidification kinetics and rheological properties of nonfat stirred yoghurt. Calcium caseinate is a protein derived from the casein in milk. The dairy industry commonly used calcium caseinate in powder form. During fermentation process, bacteria release the peptides using calcium caseinate also. Calcium is added to milk products not only for nutritional but also for functional purposes. Moreover, the calcium fortification in milk improved solubility, dialysis, transport and uptake rate of calcium, thus increasing its bioavailability, as well as enhancing heat stability of milk (Singh et al., 2007). Caseinate and WPC have been preferred in order to improve both the texture and the functional properties of yoghurt. Addition WPC and calcium caseinate in yoghurt causes 
an increase in density of the protein matrix in the gel microstructure, and reduction of syneresis in yoghurt (Amatayakul et al., 2006).

\section{Materials and Methods}

To optimize the process for production of dahi, the study involved several phases; one of them is effect of selected rate of WPC and Ca-caseinate on shelf-life study and textural profiles of dahi was prepared using $L$. rhamnosus.

\section{Materials used}

The double toned milk (DTM) was purchased from Amul Parlour, Anand, Gujarat for making dahi. Culture was obtained from the Culture Collection of Dairy Microbiology Department, SMC College of Dairy Science, Anand. WPC 70 and Ca-caseinate were procured from Charotar Casein Company, Nadiad, Gujarat.

\section{Process for manufacturing of dahi with supplementing WPC 70 and Ca-caseinate}

Double toned milk (Fat 1.5\% and SNF 9.0\%) was received from Amul Parlour, Anand. At warm temperature, WPC $70 @ 1.5 \%$ or Cacaseinate@2.0\% was added to milk. The supplemented milk was heat treated at $90^{\circ} \mathrm{C} /$ $10 \mathrm{~min}$ and mixed homogenously. The temperature of supplemented milk was lowered to $37^{\circ} \mathrm{C}$. At this stage, culture $L$. rhamnosus MTCC 5945 (NS4) was inoculated @2.0\% and filled the cups and covered with aluminum foil, then, incubated at $37^{\circ} \mathrm{C}$ for $12 \mathrm{~h}$. The final product was transferred to refrigerator $\left(7 \pm 2^{\circ} \mathrm{C}\right)$ for overnight storage. The final products obtained as above were evaluated on the basis of sensory (i.e. flavour, body and texture, acidity, colour and appearance, and overall acceptability score) and textural profiles (i.e. hardness, fracturability, cohesiveness, springiness, gumminess, resilience, adhesiveness and chewiness).

\section{Analysis}

\section{Sensory evaluation}

The product was subjected to the sensory evaluation by an expert trained panel of seven judges using nine point hedonic scale (Appendix-III). The score for colour and appearance, flavour, body and texture and overall acceptability were recorded. Fresh product at 0 day and the stored products $(5$, 10,15 days at $7 \pm 2^{\circ} \mathrm{C}$ ) were brought to $10^{\circ} \mathrm{C}$ before giving for judging (Stone and Sidel, 2004).

\section{Texture Profile Analysis (TPA)}

Texture analyser model TAHD plus made by Stable Microsystems was used for determining the textural properties of fermented milk samples. The instrument is having inbuilt software (macro) for calculations and presentation of measurements. During Texture profile analysis force is measured in compression, trigger force was $5 \mathrm{gm}$. The cylindrical probe of P36R (36 mm in diameter) was used for TPA. Pre-test, test speed and post-test speed was kept $1.0 \mathrm{~mm} / \mathrm{sec}, 1.0 \mathrm{~mm} / \mathrm{sec}$ and 2.0 $\mathrm{mm} / \mathrm{sec}$ respectively. Measurement depth was $25 \mathrm{~mm}$.

The experiments were conducted by compression test that generated plot of force (gm) vs. Time (sec), from which texture values were obtained using different formula that was programmed in TAHD plus software. The parameters were quantified and defined by Bourne (1982) which includes hardness, fracturability, cohesiveness, gumminess, springiness, adhesiveness and chewiness. These parameters were measured during 
entire period of study at previously mentioned intervals. The properties analysed are shown in Fig. 1.0. Hardness value was the peak force that occurs during the first compression. The force at the first peak was measured as fracturability. Adhesion was measured as the negative work between the two cycles. Other properties were calculated as follows.

Cohesiveness $=$ Area $2 /$ Area 1.

Springiness $=$ Distance $2 /$ Distance 1 .

Gumminess $=$ Hardness $\times$ Cohesiveness .

Resilience $=$ Area 4/Area 3 .

Chewiness $=$ Gumminess $\times$ Springiness.

\section{Statistical analysis}

The mean values generated from the analysis of dahi samples were subjected to statistical analysis using factorial completely randomized design (FCRD) as per Steel and Torrie (1980).

\section{Results and Discussion}

Effect of WPC and Ca-caseinate on sensory characteristics of dahi during storage at refrigerated temperature $\left(7 \pm 2^{\circ} \mathrm{C}\right)$

The dahi samples were studied for the estimation of shelf life at refrigerated temperature up to 15 days. Different sensory properties viz. flavour, body and texture, acidity, colour and appearance and overall acceptability were evaluated using effective testing method based on 9-point hedonic scale by seven distinguish experts panel members (Stone and Sidel, 2004).

\section{Effect on flavour}

The average flavour scores of the dahi samples prepared using NS4 during storage at refrigerated temperature $\left(7 \pm 2^{\circ} \mathrm{C}\right)$ were presented in Table 1. All parameters viz., sample, storage period and their interaction had a significant $(P<0.05)$ effect on flavour score of dahi samples. A significant $(P<0.05)$ decrease in the flavour score with increased length of storage period was observed throughout the storage study. The initial flavour score of samples decreased from 6.98 to 3.95 up to 15 days of storage at refrigerated temperature.1.5\% WPC 70 added dahi and control dahi showed acceptable flavour score (6.23 and 6.50 respectively) up to 10 days of storage as compared to $2.0 \%$ Ca-caseinate. Defects such as bitterness and off flavour were perceived in case of dahi sample prepared using $2.0 \% \mathrm{Ca}$-caseinate during the storage (Table 1). Zhao et al., (2006) reported sensory evaluation scores on the flavor, the body and texture, and the color and appearance of the yogurts fortified with casein hydrolysates decreased by storage time (upto 28 days). This report supported our study whenever we prepared dahi by supplementing $2.0 \% \mathrm{Ca}$-caseinate, the flavour score decreased throughout the storage periods.

\section{Effect on body and texture}

The average body and texture scores of dahi samples prepared using NS4 during storage at refrigerated temperature $\left(7 \pm 2^{\circ} \mathrm{C}\right)$ were presented in Table 1. All parameters viz., sample, storage period and their interaction had a significant $(P<0.05)$ effect on body and texture score of dahi samples. A significant $(P<0.05)$ decrease in the body and texture score with increased length of storage period was observed throughout the storage study. The initial body and texture score of samples decreased from 7.49 to 5.43 up to 15 days of storage at refrigerated temperature. Sample prepared using $1.5 \%$ WPC exhibited good firmness with no whey separation up to 15 days whereas sample prepared with $2.0 \% \mathrm{Ca}-$ caseinate showed whey separation after 5 days of storage (Table 1). In a study, Marafon et al., (2011) reported that the supplementation of the milk base with milk 
proteins increased the consistency of the probiotic yogurt in terms of sensory attributes. This report supported our data whenever prepared dahi by supplementing $1.5 \%$ WPC upto 10 days of storage.

\section{Effect on acidity}

The average acidity scores of dahi samples prepared using NS4 during storage at refrigerated temperature $\left(7 \pm 2^{\circ} \mathrm{C}\right)$ were presented in Table 1. All parameters viz., sample, storage period and their interaction had a significant $(P<0.05)$ effect on acidity score of dahi samples. A significant $(P<0.05)$ decrease in the acidity score with increased length of storage period was observed throughout the storage study. The initial acidity score of samples decreased from 6.74 to 3.84 up to 15 days of storage at refrigerated temperature. 1.5\%WPC added dahi and control dahi showed acceptable acidity score (6.43 and 6.40 respectively) up to 5 days of storage as compared to $2.0 \%$ Ca-caseinate added dahi (Table 1). In a study, Chick et al., (2001) studied the control sample had higher lactic acid content than the $1.0 \%$ WPC yoghurt sample on the first day of storage $(\mathrm{P}<0.05)$. This report supported our data whenever we prepared dahi by supplementing $1.5 \%$ WPC.

\section{Effect on colour and appearance}

The average colour and appearance scores of dahi samples prepared using NS4 culture during storage at refrigerated temperature $\left(7 \pm 2^{\circ} \mathrm{C}\right)$ were presented in Table 1. All parameters viz., sample, storage period and their interaction had a significant $(P<0.05)$ effect on colour and appearance score of dahi samples. The initial colour and appearance score of samples decreased from 7.69 to 5.17 up to 15 days of storage at refrigerated temperature. A significant $(P<0.05)$ decrease in the colour and appearance score with increased length of storage period was observed throughout the storage study. 1.5\%WPC added dahi showed acceptable colour and appearance score 6.10 upto 15 days and control dahi showed 7.05 upto 10 days of storage compared to $2.0 \% \mathrm{Ca}$ caseinate added dahi (Table 1). In a study, Zhao et al., (2006) reported sensory evaluation scores on the flavor, the body and texture, and the color and appearance of the yogurts fortified with casein hydrolysates decreased by storage time (up to 28 days). This report supported our data whenever prepared dahi by supplementing $2.0 \% \mathrm{Ca}-$ caseinate.

\section{Effect on overall acceptability}

The average overall acceptability scores of dahi samples prepared using NS4 during storage at refrigerated temperature $\left(7 \pm 2^{\circ} \mathrm{C}\right)$ were presented in Table 1. All parameters viz., sample, storage period and their interaction had a significant $(P<0.05)$ effect on overall acceptability score of dahi samples. A significant $(P<0.05)$ decrease in the overall acceptability score with increased length of storage period was observed throughout the storage study. The initial overall acceptability score of samples decreased from 7.12 to 4.44 up to 15 days of storage at refrigerated temperature. The lower average score of sample prepared using $2.0 \%$ Ca-caseinate might be because of little bit whey separation, loose body \& texture and unacceptable flavour during the storage (Table 1).

In a study, Martín-Diana et al., (2003) studied cow's fermented milk had a low grading for appearance due to wheying-off on the fermented milk surface. The fermented goat's milk supplemented with $3.0 \%$ WPC was scored the highest, showing a high overall acceptability, similar to that for cow's fermented milk. This report supported our data whenever prepared dahi by supplementing $1.5 \%$ WPC. 
Effect of WPC and Ca-caseinate on textural analysis of dahi during storage at refrigerated temperature $\left(7 \pm 2^{\circ} \mathrm{C}\right)$

The dahi samples prepared with $1.5 \%$ WPC 70 and $2.0 \% \mathrm{Ca}$-caseinate were inoculated with $2.0 \% \mathrm{NS} 4$ culture and incubated at $37^{\circ} \mathrm{C}$ for $12 \mathrm{~h}$. The samples were stored at refrigerated temperature. Determination of texture properties (i.e. hardness, fracturability, cohesiveness, springiness, gumminess, resilience, adhesiveness and chewiness) of samples at the interval of 0 day, 5 days, 10 days and 15 days.

\section{Changes in hardness (g)}

The effect of WPC 70 and Ca-caseinate on hardness of samples prepared using NS4 during storage at refrigerated temperature $\left(7 \pm 2^{\circ} \mathrm{C}\right)$ were exhibited in Table 2. Storage period, sample and their interaction had a significant effect on hardness of samples. The average hardness of all samples increased significantly $\quad(P<0.05) \quad$ was observed throughout the storage period. The initial average hardness of samples had been increased from $146.12 \mathrm{~g}$ to $169.76 \mathrm{~g}$ up to 15 days of storage at refrigerated temperature. In a study, Akalın et al., (2012) reported fortification with $\mathrm{SCaCN}$ (sodium calcium caseinate) has been found to increase the firmness more than WPC in probiotic yogurts during storage $(\mathrm{P}<0.05)$. These results are in agreement with the results of GuzmánGonzález et al., (1999) who reported that casein-based products tended to produce firmer gels with less syneresis than yogurts fortified with whey protein. This report supported our data whenever we prepared dahi by supplementing $2.0 \%$ Ca-caseinate.

\section{Changes in fracturability (g)}

The effect of WPC 70 and Ca-caseinate on fracturability $(\mathrm{g})$ of samples prepared using
NS4 during storage at refrigerated temperature $\left(7 \pm 2^{\circ} \mathrm{C}\right)$ were shown in Table 2.Storage period, sample and their interaction had a significant $(P<0.05)$ effect on fracturability of samples. The average fracturability of all samples increased significantly $(P<0.05)$ was found throughout the storage period. The initial average fracturability of samples had been increased from $130.75 \mathrm{~g}$ to $157.23 \mathrm{~g}$ up to 15 days of storage at refrigerated temperature. In a study, Sodini et al., (2004) reported that when the milk base was supplemented with proteins obtained from ultrafiltration, WPC, or caseinate, the firmness of the yogurts increased compared with a product fortified with SMP. This was due to the increase of the protein content in relation to the TS level. This report supported our data whenever $d a h i$ was prepared by supplementing $1.5 \%$ WPC and $2.0 \% \mathrm{Ca}$-caseinate.

\section{Changes in cohesiveness}

The effect of WPC 70 and Ca-caseinate on cohesiveness of samples prepared using NS4 during storage at refrigerated temperature $\left(7 \pm 2^{\circ} \mathrm{C}\right)$ were shown in Table 2 . Both storage period and sample had a significant $(P<0.05)$ effect but their interaction had a nonsignificant effect on cohesiveness of samples. The average cohesiveness of all samples increased significantly $(P<0.05)$ was observed throughout the storage period.

The initial average cohesiveness of samples had been increased from 0.47 to 0.53 up to 15 days of storage at refrigerated temperature. In a study, Landge (2009) reported the yogurt texture parameters i.e. adhesiveness, cohesiveness, firmness and syneresis were not influenced by the storage time. The above reports are contradictory to our study whenever dahi was prepared by supplementing $1.5 \% \mathrm{WPC}$ and $2.0 \% \mathrm{Ca}-$ caseinate. 


\section{Changes in springiness}

The effect of WPC 70 and Ca-caseinate on springiness of samples prepared using NS4 during storage at refrigerated temperature $\left(7 \pm 2^{\circ} \mathrm{C}\right)$ were shown in Table 2 . Both storage period and sample had a significant $(P<0.05)$ effect but their interaction had a nonsignificant effect on springiness of samples. The average springiness of all samples increased significantly $(P<0.05)$ was found throughout the storage period. The initial average springiness of samples had been increased from 1.00 to 1.04 after 15 days of storage at refrigerated temperature. In a study, Akalın et al., (2012) reported milk fortification had an effect on the WHC (water holding capacity) of yogurts, which varied from 68.78 to $43.22 \%$. The higher WHC was obtained for yogurts made using milks fortified with WPC and then with blends of WPC and $\mathrm{SCaCN}$, representing the values of 68.78 and $59.38 \%$, respectively, for the first day. The separate use of caseinate to fortify milk gave yogurts with lower WHC similar to the control samples.

\section{Changes in gumminess (g)}

The effect of WPC 70 and Ca-caseinate on gumminess ( $\mathrm{g}$ ) of samples prepared using NS4 during storage at refrigerated temperature $\left(7 \pm 2^{\circ} \mathrm{C}\right)$ were presented in Table 2. Storage period, sample and their interaction had a significant effect on gumminess of samples. The average gumminess of all samples increased significantly $(P<0.05)$ was observed throughout the storage period. The initial average gumminess of samples had been increased from $62.95 \mathrm{~g}$ to $85.03 \mathrm{~g}$ up to 15 days of storage at refrigerated temperature. In a study, Sady et al., (2009) reported the type of kefir did not have significant influence on the texture parameter obtained from TPA analysis. Hardness and gumminess of kefir had changed significantly after 21 st day of storage. During storage these both parameters systematically grew and got the maximum value at the end of storage period. Supplementation of milk solid for kefir caused increase of the adhesiveness of products. The highest value of this parameter got product with SMP. Although, there were no statistically significant differences during the storage, after 7 days kefir had a maximal value of adhesiveness. This report supported our study whenever dahi was prepared by supplementing $1.5 \% \mathrm{WPC}$ and $2.0 \% \mathrm{Ca}-$ caseinate.

\section{Changes in resilience}

The effect of WPC 70 and Ca-caseinate on resilience of samples prepared using NS4 during storage at refrigerated temperature $\left(7 \pm 2^{\circ} \mathrm{C}\right)$ were shown in Table 2. Storage period and sample had a significant $(P<0.05)$ effect but their interaction had a nonsignificant effect on resilience of samples. The initial average resilience of samples had been increased from 0.08 to 0.13 up to 15 days of storage at refrigerated temperature. In a study, Stijepic et al., (2012) reported significantly higher WHC, with about $30 \%$ higher value of WHC, had the yoghurt samples with WPC and combination of WPC and WPC and honey whose WHC slightly decreased during the storage time. WPC had significantly increased water-holding capacity even at 0.3 or $0.5 \%$ addition and it was about $75 \%$ (Milanovic et al., 2009). Stable values of WHC of yoghurt samples enriched with WPC during the storage time could be explained by the fact that WHC can be increased by adding stabilizers that interact with the casein network, which in this case is WPC, but also honey.

\section{Changes in adhesiveness (g)}

The effect of WPC 70 and Ca-caseinate on adhesiveness ( $\mathrm{g}$ ) of samples prepared using 
NS4 during storage at refrigerated temperature $\left(7 \pm 2^{\circ} \mathrm{C}\right)$ were shown in Table 2 . Storage period, sample and their interaction had a significant $(P<0.05)$ effect on adhesiveness of samples. The average adhesiveness of all samples increased significantly $(P<0.05)$ throughout the storage period. The initial average adhesiveness of samples had been increased from $177.46 \mathrm{~g}$ to $313.83 \mathrm{~g}$ up to 15 days of storage at refrigerated temperature. In a study, Akalin et al., (2012) studied the influence of milk protein-based ingredients on the textural characteristics, sensory properties, and microstructure of probiotic yogurt during a refrigerated storage period of $28 \mathrm{~d}$ was studied. Milk was fortified with $2.0 \%$ (wt/vol) skim milk powder as control, $2.0 \%$ (wt/vol) sodium calcium caseinate $(\mathrm{SCaCN}), 2.0 \%$ (wt/vol) whey protein concentrate (WPC) or a blend of $1.0 \%(\mathrm{wt} / \mathrm{vol}) \mathrm{SCaCN}$ and $1.0 \%$ (wt/vol) WPC. A commercial yogurt starter culture and Bifidobacterium lactis $\mathrm{Bb} 12$ as probiotic bacteria were used for the production. The fortification with $\mathrm{SCaCN}$ improved the firmness and adhesiveness. This report supported our study whenever dahi was prepared by supplementing $2.0 \% \quad \mathrm{Ca}-$ caseinate.

Table.1 Changes in the sensory attributes* of dahi prepared using NS4 during storage at refrigerated temperature $\left(7 \pm 2^{\circ} \mathrm{C}\right)$

\begin{tabular}{|c|c|c|c|c|c|c|c|c|c|}
\hline \multirow{2}{*}{ Attribute } & \multirow{2}{*}{ Sample } & \multicolumn{4}{|c|}{ Storage period (days) } & \multirow{2}{*}{$\begin{array}{l}C^{C D_{0.05}} \\
\mathrm{~A}\end{array}$} & \multirow{2}{*}{$\begin{array}{l}\mathrm{CD}_{0.05} \\
\mathrm{~B}\end{array}$} & \multirow{2}{*}{$\mathrm{CD}_{0.05} \mathrm{~A} * \mathrm{~B}$} & \multirow{2}{*}{$\begin{array}{l}\text { F- } \\
\text { value }\end{array}$} \\
\hline & & $\mathbf{0}$ & 5 & 10 & 15 & & & & \\
\hline \multirow{4}{*}{ Flavour } & Control & $7.25 \pm 0.05$ & $6.70 \pm 0.10$ & $6.23 \pm 0.06$ & $4.00 \pm 0.10$ & \multirow{4}{*}{0.06} & \multirow{4}{*}{0.07} & \multirow{4}{*}{0.12} & \multirow{4}{*}{1.30} \\
\hline & $1.5 \% \mathrm{WPC}$ & $7.63 \pm 0.06$ & $7.15 \pm 0.05$ & $6.50 \pm 0.11$ & $5.40 \pm 0.10$ & & & & \\
\hline & $2 \%$ Ca- & $6.05 \pm 0.05$ & $3.45 \pm 0.07$ & $3.15 \pm 0.05$ & $2.45 \pm 0.05$ & & & & \\
\hline & Mean & 6.98 & 5.77 & 5.29 & 3.95 & & & & \\
\hline \multirow{4}{*}{$\begin{array}{l}\text { Body and } \\
\text { texture }\end{array}$} & Control & $7.63 \pm 0.15$ & $7.30 \pm 0.10$ & $6.87 \pm 0.15$ & $6.30 \pm 0.30$ & \multirow{4}{*}{0.14} & \multirow{4}{*}{0.17} & \multirow{4}{*}{0.29} & \multirow{4}{*}{2.61} \\
\hline & $1.5 \% \mathrm{WPC}$ & $7.85 \pm 0.05$ & $8.15 \pm 0.05$ & $7.65 \pm 0.05$ & $6.77 \pm 0.25$ & & & & \\
\hline & $2 \% \mathrm{Ca}-$ & $7.00 \pm 0.10$ & $6.00 \pm 0.20$ & $4.27 \pm 0.15$ & $3.23 \pm 0.25$ & & & & \\
\hline & Mean & 7.49 & 7.15 & 6.26 & 5.43 & & & & \\
\hline \multirow{3}{*}{ Acidity } & Control & $6.75 \pm 0.15$ & $6.40 \pm 0.10$ & $5.83 \pm 0.15$ & $4.23 \pm 0.25$ & \multirow{3}{*}{0.14} & \multirow{3}{*}{0.16} & \multirow{3}{*}{0.27} & \multirow{3}{*}{3.03} \\
\hline & $1.5 \% \mathrm{WPC}$ & $6.85 \pm 0.15$ & $6.43 \pm 0.21$ & $5.90 \pm 0.10$ & $4.60 \pm 0.12$ & & & & \\
\hline & $\begin{array}{l}\text { caseinate } \\
\text { Mean }\end{array}$ & $\begin{array}{c}6.63 \pm 0.15 \\
\mathbf{6 . 7 4}\end{array}$ & $\begin{array}{c}4.13 \pm 0.15 \\
\mathbf{5 . 6 6}\end{array}$ & $\begin{array}{c}3.73 \pm 0.17 \\
\mathbf{5 . 1 6}\end{array}$ & $\begin{array}{c}2.70 \pm 0.20 \\
\mathbf{3 . 8 4}\end{array}$ & & & & \\
\hline \multirow{4}{*}{$\begin{array}{l}\text { Colour and } \\
\text { appearance }\end{array}$} & Control & $7.90 \pm 0.10$ & $7.70 \pm 0.10$ & $7.05 \pm 0.17$ & $5.30 \pm 0.10$ & \multirow{4}{*}{0.12} & \multirow{4}{*}{0.14} & \multirow{4}{*}{0.25} & \multirow{4}{*}{2.24} \\
\hline & $1.5 \% \mathrm{WPC}$ & $8.05 \pm 0.15$ & $7.70 \pm 0.10$ & $7.20 \pm 0.10$ & $6.10 \pm 0.26$ & & & & \\
\hline & $\begin{array}{l}2 \% \quad \mathrm{Ca}- \\
\text { caseinate }\end{array}$ & $7.13 \pm 0.15$ & $6.03 \pm 0.16$ & $4.70 \pm 0.20$ & $4.10 \pm 0.10$ & & & & \\
\hline & Mean & 7.69 & 7.14 & 6.32 & 5.17 & & & & \\
\hline \multirow{4}{*}{$\begin{array}{l}\text { Overall } \\
\text { acceptability }\end{array}$} & Control & $7.25 \pm 0.05$ & $7.07 \pm 0.15$ & $6.70 \pm 0.20$ & $5.10 \pm 0.20$ & \multirow{4}{*}{0.13} & \multirow{4}{*}{0.15} & \multirow{4}{*}{0.27} & \multirow{4}{*}{2.62} \\
\hline & $1.5 \% \mathrm{WPC}$ & $7.90 \pm 0.10$ & $7.60 \pm 0.10$ & $6.87 \pm 0.15$ & $5.30 \pm 0.20$ & & & & \\
\hline & $\begin{array}{l}2 \% \text { Ca- } \\
\text { caseinate }\end{array}$ & $6.20 \pm 0.10$ & $4.97 \pm 0.15$ & $3.90 \pm 0.22$ & $2.93 \pm 0.25$ & & & & \\
\hline & Mean & 7.12 & 6.54 & 5.82 & 4.44 & & & & \\
\hline
\end{tabular}

*mean values; $n=3$; A- sample; B- storage period; CD- critical difference 
Table.2 Changes in textural profilesof dahi prepared using NS4 during storage at refrigerated temperature $\left(7 \pm 2^{\circ} \mathrm{C}\right)$

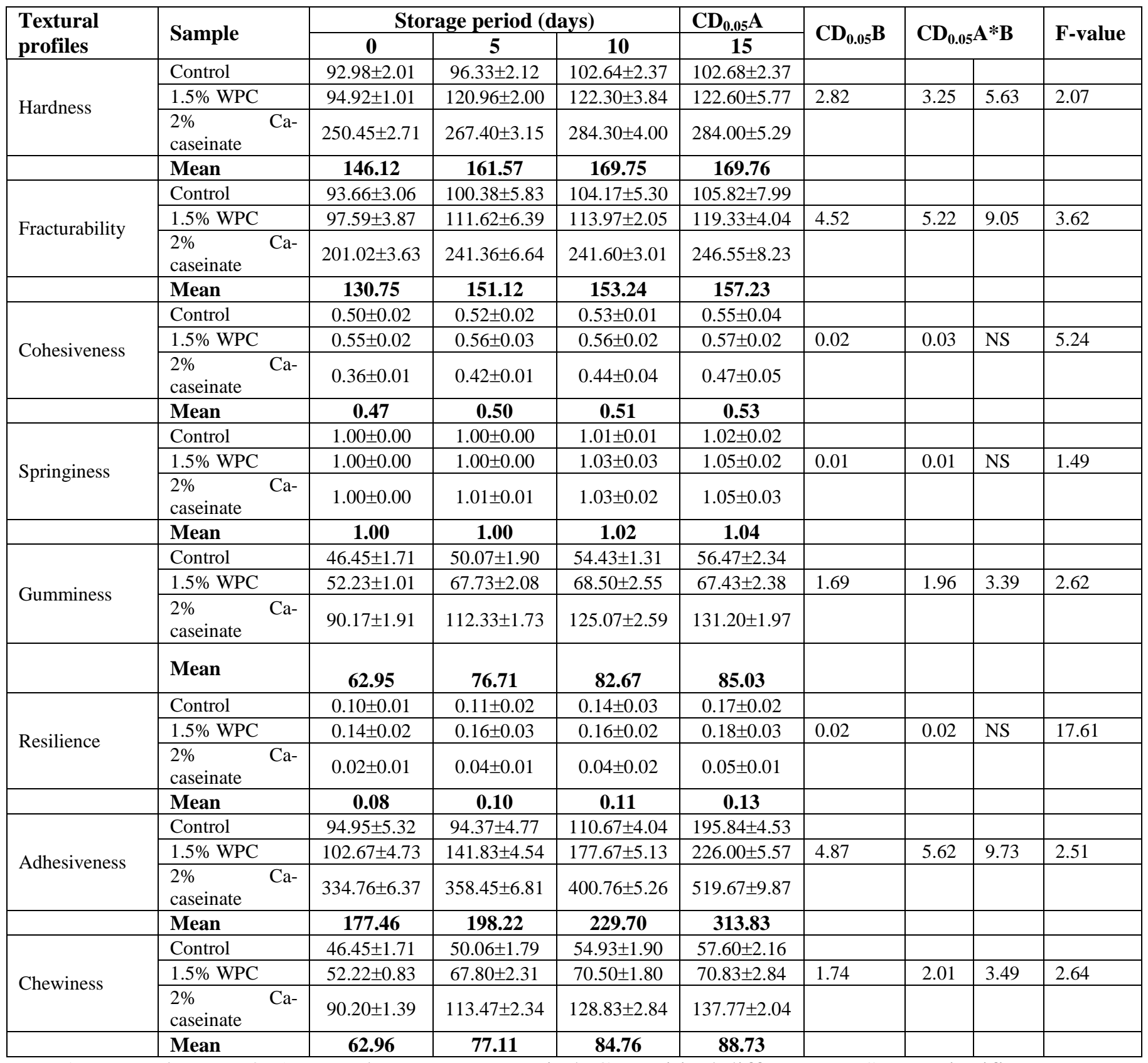

*mean values; $\mathrm{n}=3$; A- sample; B- storage period; CD- critical difference; NS- non significant 
Fig.1 Two cyclic graph for texture profile analysis

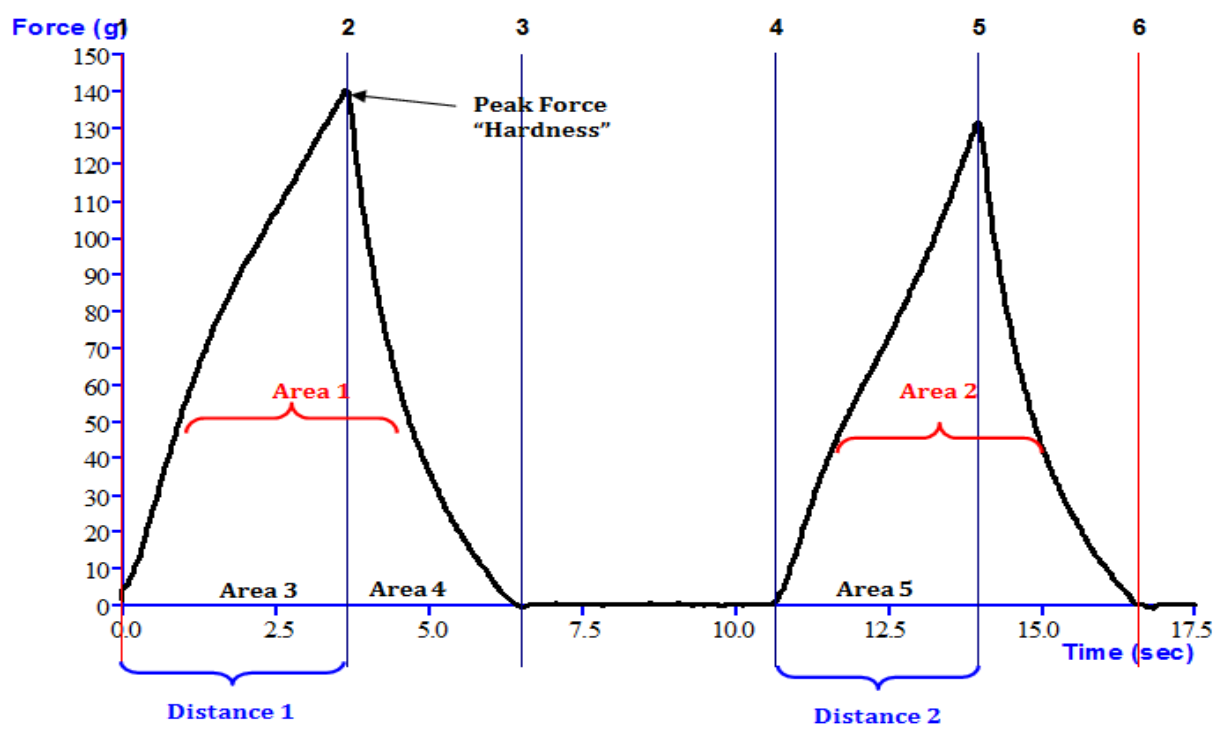

Fig.2 Textural profiles of dahi prepared with 2.0\% Ca-caseinate using NS4 after 15 days of

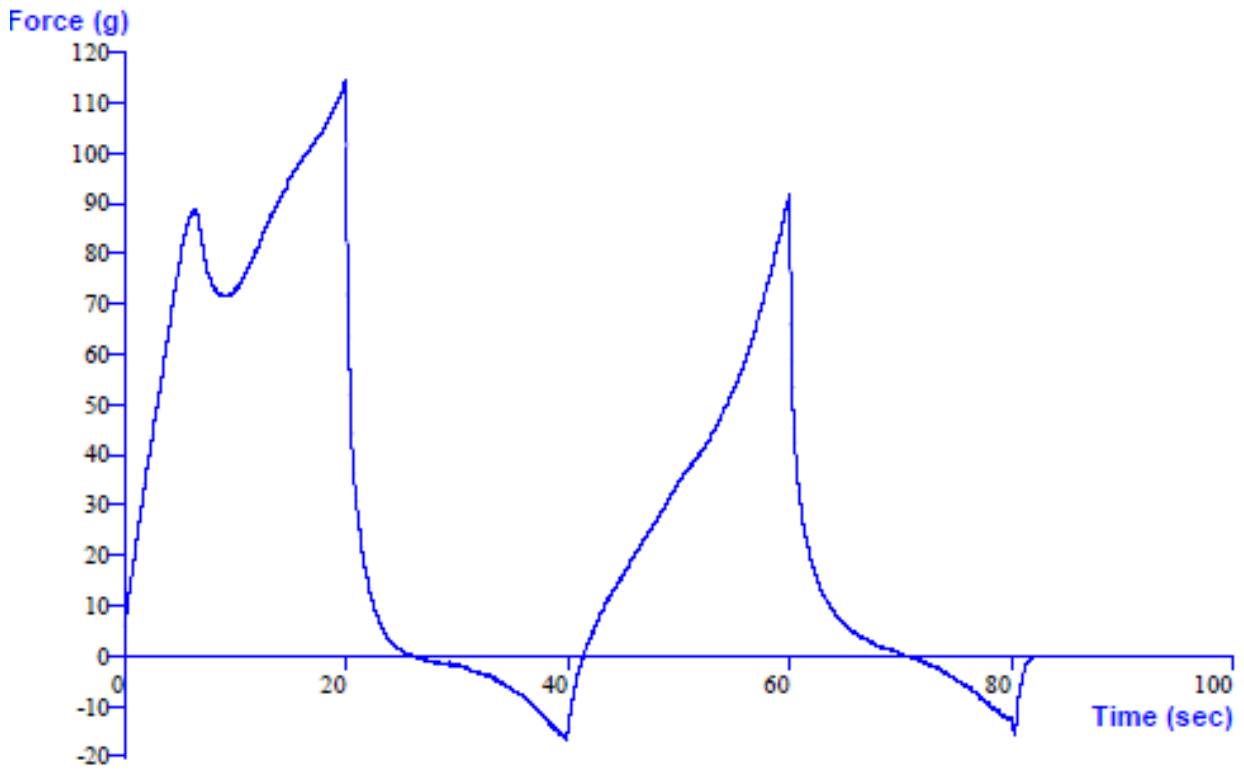

\section{Changes in chewiness (g)}

The effect of WPC 70 and Ca-caseinate on chewiness ( $\mathrm{g}$ ) of samples prepared using NS4 during storage at refrigerated temperature $\left(7 \pm 2^{\circ} \mathrm{C}\right)$ were presented in Table 2. Storage period, sample and their interaction had a significant $(P<0.05)$ effect on chewiness of samples. The average chewiness of all samples increased significantly $(P<0.05)$ was observed throughout the storage period. The initial average chewiness of samples had been increased from $62.96 \mathrm{~g}$ to $88.73 \mathrm{~g}$ up to 15 days of storage at refrigerated temperature. In a study, Marafon et al., (2011) reported that the rheological properties of probiotic yogurts were greatly enhanced when SMP was partially replaced with WPC and SC. This 
report supported our study whenever dahi was prepared by supplementing $1.5 \% \mathrm{WPC}$.

In conclusion, it was observed that the $1.5 \%$ WPC 70 was more convenient for manufacture of dahi and this level was selected for product. All the parameters of sensory profile showed that $1.5 \%$ WPC 70 supplemented in dahi samples were more acceptable as compared to control and $2.0 \%$ Ca-caseinate supplemented dahi. All the parameters of textural profile showed that $1.5 \%$ WPC 70 supplemented in dahi samples showed better texture properties as compared to control and $2.0 \% \mathrm{Ca}$-caseinate during storage at refrigerated temperature $\left(7 \pm 2^{\circ} \mathrm{C}\right)$.

\section{Acknowledgements}

The authors are thankful to the Professor and Head, Dept. of Dairy Microbiology and Dean, SMC College of Dairy Science for providing facilities to carry out this work.

\section{References}

Akalin, A.S., G. Unal, N. Dinkci and A.A. Hayaloglu. 2012. Microstructural, textural, and sensory characteristics of probiotic yogurts fortified with sodium calcium caseinate or whey protein concentrate. J. Dairy Sci., 95(7): 36173628

Akalin, A.S., S. Gönç, G. Ünal and S. Fenderya. 2007. Effects of fructo-oligosaccharide and whey protein concentrate on the viability of starter culture in reduced fat probiotic yogurt during storage. $J . F d$ Sci., 72: 222-227.

Amatayakul, T.F., F. Sherkat and N.P. Shah. 2006. Physical characteristics of set yoghurt made with altered casein to whey protein ratios and EPS producing starter cultures at 9 and $14 \%$ total solids. $F d$ Hydrocolloids, 20: 314-324.

Behare, P.V. and J.B. Prajapati. 2007. Thermization as a method for enhancing the shelf life of cultured butter milk.
Indian J. Dairy Sci., 60: 86-93.

Bourne, M.C. 1982. Food Texture and Viscosity: Concept and Measurement. Academic

Chick, H., H.S. Shin and Z. Ustunol. 2001. Growth and acid production by lactic acid bacteria and bifidobacteria in skim milk containing honey. J. Fd Sci., 66: 478-481.

Christensen, J.E., E.G. Dudley, J.A. Pedersonn and J.L. Steele. (1999). Peptidases and amino acid catabolism in lactic acid bacteria. Ant. van Leeuwenhoek, 76: 217246.

Damin, M.R., M.R. Alcantara, A.P. Nunes and M.N. Oliveira. 2009. Effects of milk supplementation with skim milk powder, whey protein concentrate and sodium caseinate on acidification kinetics, rheological properties and structure of non fat stirred yogurt. $L W T-F d S c i$. Tech., 42: 1744-1750.

Gahruie, H.H., M.H. Eskandaria, G. Mesbahi and M.A. Hanifpourb. 2015. Scientific and technical aspects of yogurt fortification: A review. Fd Sci. Human Well, 4: 1-8.

Guzmán-González M., F. Morais, M. Ramos and L. Amigo. 1999. Influence of skimmed milk concentrate replacement by dry dairy products in a low fat set-type yoghurt model system. I: Use of whey protein concentrates, milk protein concentrates and skimmed milk powder. J. Sci. Fd Agri., 79: 1117-1122.

Landge, V.L. 2009. Quality of yogurt supplemented with whey protein concentrate and effects of whey protein denaturation. A thesis master of science. Kansas state university, Manhattan, Kansas.

Marafon, A.P., A. Sumi, M.R. Alcântara, A.Y. Tamime and M.N. de Oliveira. 2011. Optimization of the rheological properties of probiotic yoghurts supplemented with milk proteins. LWT - Fd Sci. Tech., 44: 511-519.

Martín-Diana, A.B., C. Janer, C. Peláez and T. Requena. 2003. Development of a fermented goat's milk containing 
probiotic bacteria. Int. Dairy J., 13(10): 827-833.

Milanović, S., M. Iličić, M. Đurić and M. Carić. 2009. Effect of transglutaminase and whey protein concentrate on textural characteristics of low fat probiotic yoghurt. Milchwissenschaft - Milk Sci. Int., 64: 388-392.

Miyazaki, K. and T. Matsuzaki. 2008. Health Properties of Milk Fermented with Lactobacillus casei strain Shirota (LcS). In: Handbook of Fermented Functional Food, (Eds.) Farnworth E.R.E. 165-208.

N.D.D.B. 2014. web.thehindu@ thehindu.co.in

Pal, S., V. Ellis and S. Dhaliwal. 2010. Effects of whey protein isolate on body composition, lipids, insulin and glucose in overweight and obese individuals. $\mathrm{Br}$. J. Nutr., 104: 716-723.

Sady, M., J. Domagala, D. Najgebauer-Lejko and T. Grega. 2009. Effect of whey protein concentrate addition on texture and rheological properties of kefir produced from skimmed milk. Biotechnol. Anim. Husb., 25(5-6): $763-$ 771.

Singh, G., S. Arora, G.S. Sharma, J.S. Sindhu, V.K. Kansal and R.B. Sangwan. 2007. Heat stability and calcium bioavailability of calcium-fortified milk. LWT-Fd Sci. Technol., 40(4): 625-631.

Singh, R. 2007. Characterization and Technology of Traditional Indian Cultured Dairy Products. Bull. Int. Dairy Fed., 415: 11-20.

Sodini, I., F. Remeuf, S. Haddad and G. Corrieu. 2004. The relative effect of milk base, starter and process on yoghurt texture. Crit. Rev. Fd Sci. Nutr., 44: 113137.

Steel, R.G.D. and J.H. Torrie. 1980. Principles and procedure of statistics - a biometrical approach. 2nd (Ed.), pp. 137. McGrawHill Kogakusha Ltd., Japan.

Stijepic, M., S. Milanovic, D. DjurdjevićMiloševic, M. Đurić, J. Glušac, K. Kanuric, V.V. Vukic. 2012. Effects of honey and whey protein concentrate addition on textural and sensory properties of probiotic yoghurt. Milchwissenschaft, 67: 277-280.

Stone, H. and J.L. Sidel. 2004. Sensory evaluation practices, 3rd edition, Tragon Corporation, Ca. USA.

Tamime, A.Y. and R.K. Robinson. 1999. Nutritional value of yoghurt. In: Yoghurt Science and Technology, (Eds.) Tamime, A.Y. and R.K. Robinson. 515-534. Second edition, Wood head Publishing Ltd and CRC Press LLC.

Vasiljevic, T., N.P. Shah and P. Jelen. 2005. Growth characteristics of Lactobacillus delbrueckii subsp. Bulgaricus ATCC 11842 as affected by different neutralizers. Aust. J. Dairy Technol., 60: 3-9.

Yadav, H., J. Shalini and P.R. Sinha. 2006. Effect of dahi containing Lactococcus lactis on the progression of diabetes induced by a high fructose diet in rats. Biosci. Biotechnol. Biochem., 70: 12551258.

Yadav, H., J. Shalini and P.R. Sinha. 2007. Formation of oligosaccharides in skim milk fermented with mixed dahi cultures, Lactococcus lactis subsp. diacetylactis and probiotic strains of lactobacilli. J Dairy Res., 74: 154-159.

Zhao, Q.Z., Wang, J.S., Zhao, M.M., Jiang, Y.M. and Chun, C. 2006. Effect of casein hydrolysates on yoghurt fermentation and texture properties during storage. $F d$ Tech. Biotech., 44: 429-434.

\section{How to cite this article:}

Rekha S. Patel and Subrota Hati. 2017. Importance of WPC 70 and Calcium Caseinate on Sensory and Textural Properties of Milk Fermented with L. rhamnosus. Int.J.Curr.Microbiol.App.Sci. 6(5): 618-629. doi: https://doi.org/10.20546/ijcmas.2017.605.072 